\title{
wfpha
}

The Federation's Pages

\author{
WFPHA: World Federation of Public Health Associations \\ www.wfpha.org \\ Bettina Borisch, Federation's Pages Editor
}

Journal of Public Health Policy (2016). doi:10.1057/s41271-016-0017-0

\section{Health Sector Reform: Time to Introspect}

Key questions raised:

1. Does Performance-Based Finance solve the problem of underutilization of services?

2. Has scaling up program of health sector reform been balanced and matching?

3. Are Inter and Intra-household inequalities addressed and reduction attempted?

\section{Performance-Based Finance - Does It Solve the Problem of Underutilization of Services?}

Performance-Based Finance was one of the reforms undertaken in the Health Sector, launched under a similar philosophical and implementation framework across most developing countries. While the World Bank Report (1993), ${ }^{1}$ printed the first thoughts about this reform, the ideas appeared earlier, in the mid-1980s as major economic crises ransacked many developing regions and tight-fisted fiscal austerity under macroeconomic policies produced scarcity of resources, inefficient management, absence of monitoring as well as inequitable distribution in the public financed health care system.

Influenced by management reforms in the United States (US) and United Kingdom (UK) health sector, many developing countries, under the tutelage of international agencies like World Bank and World Health Organization, attempted to redefine relationships among states, service providers, users,

The content of The Federation's pages is selected and edited by the WFPHA and not sent through JPHP's usual process of peer review. 
and other health-related organizations, such as hospital boards and private sector providers of goods and services. ${ }^{2}$

In the name of health care reform, controlling the knobs of financial mechanisms gained crucial importance. ${ }^{3}$ Reduced reliance on public financing and greater emphasis on Public Private Partnership (PPP) mechanisms were expected, by the framers of this approach, to improve cost control and increase cost recovery, along with decentralization at the community level, addition of Performance Based Finance (PBF) to the front line health workers, and incentive schemes for the beneficiaries.

However, with user charges introduced in public sector, the cost of health care, particularly for the poorest, rose without limits in India, pushing the already impoverished into a 'Medical Poverty Trap'.

Looking back, after more than a decade of these reforms, gains appear to be far less than expected and concerns have evolved for both equity and efficiency.

In India, the PBF system did enhance service utilization, but also resulted in severe inequity and potential adverse effect on related, but non-incentivized services like use of contraception methods, nutritional awareness etc. ${ }^{4,5}$ For the providers, who receive PBF, the 'units of service' remain the baby and pregnant mothers pre-dominantly. This discouraged providers from making the women aware of contraception opportunities and choice. PPP programs usually ended in reaping private benefits at the government's cost, taking full advantage of opening unregulated markets for health care delivery.

\section{Scaling Up Program of Health Sector Reform - Have They been Balanced and Matching}

Experiences in many developing countries reveal that, from the provider's perspective, scaling up programs has meant "doing something in a big way to improve some aspect of a population's health", ${ }^{n}$ in many countries the big push in infrastructure has not been commensurate with expansion of workforce or vice-versa. Even though more hospitals are created, it is not matched with more doctors and nurses - hence utilization of new hospital beds remains less than optimal and automatically the output stagnates. Thus without reaping the benefits of 'scale effect', when all the inputs are increased in a fixed proportion, the production will continue to remain at the initial levels. A quick look at the finance and input positions across countries in the region would be illuminating. For simple convenience, we focus on certain countries in Asia, often identified as the most critical zone in terms of health status. 
Table 1: \% of government expenditure on health as total expenditure on health, 2000-2009 ${ }^{8}$

\begin{tabular}{|c|c|c|c|c|c|c|c|c|c|c|c|}
\hline & 2000 & $200 I$ & 2002 & 2003 & 2004 & 2005 & 2006 & 2007 & 2008 & 2009 & $\begin{array}{l}\text { Growth } \\
\text { rate } \\
\text { from } \\
2000 \text { to } \\
2009 \%\end{array}$ \\
\hline Nepal & $35 \cdot 3$ & $37 \cdot 7$ & 36 & 27.8 & 23.9 & $23 \cdot 4$ & $26 . I$ & 30.7 & 24 & $24 \cdot 9$ & $-4 \mathrm{I} .8$ \\
\hline Vietnam & 38.7 & 38.5 & $39 \cdot 3$ & 32.3 & $25 \cdot 9$ & 26.8 & $3 \mathrm{I} \cdot 4$ & 30 & $3 I$ & 30.1 & -28.6 \\
\hline Bangladesh & 39 & 39.9 & 39.7 & 37.6 & 38.8 & $34 \cdot 9$ & 36.5 & $34 \cdot 4$ & $3 \mathrm{I} \cdot 4$ & 31.7 & -23.0 \\
\hline India & $27 \cdot 5$ & $27 \cdot I$ & 25 & $25 \cdot 7$ & 22.5 & 23 & $27 \cdot 5$ & 29.6 & 32.4 & 32.8 & I 6.2 \\
\hline Pakistan & $2 \mathrm{I} .2$ & 20.4 & 28 & 22.9 & 23.9 & $25 . \mathrm{I}$ & 29.8 & 29.9 & 32.3 & 32.8 & $35 \cdot 4$ \\
\hline Indonesia & $5 \mathrm{I} .8$ & $54 \cdot 4$ & 54.2 & $49 \cdot 3$ & 48.5 & $39 \cdot 5$ & $40 . \mathrm{I}$ & $38 . \mathrm{I}$ & $43 \cdot 5$ & 36.6 & $-4 I \cdot 5$ \\
\hline Sri Lanka & 48.3 & 46 & $43 \cdot 7$ & $4 \mathrm{I} \cdot 7$ & 46.2 & 46.6 & $47 \cdot 7$ & 48.7 & $43 \cdot 7$ & $45 \cdot 2$ & -6.9 \\
\hline Philippines & $35 \cdot 3$ & $35 \cdot \mathrm{I}$ & 34.8 & $35 \cdot 4$ & 39.2 & 38.5 & 40.2 & 40 & 44.2 & 47.6 & 25.8 \\
\hline China & 38.3 & 35.6 & 35.8 & 36.2 & 38 & 38.8 & 40.7 & $45 \cdot 3$ & $47 \cdot 3$ & 50.1 & 23.6 \\
\hline Malaysia & 44.8 & 42.9 & $44 \cdot 5$ & 44.6 & 44.8 & 50 & 56.4 & $55 \cdot 4$ & 55.8 & 52.4 & I $4 \cdot 5$ \\
\hline Thailand & 75.8 & $74 \cdot 3$ & 72.3 & 68 & $64 \cdot 4$ & $64 \cdot 9$ & 63.8 & 63.5 & 56.4 & 56.1 & $-35 \cdot I$ \\
\hline Bhutan & 81.9 & 82.5 & $8 \mathrm{I} .7$ & 80.9 & 76.4 & 72.5 & $74 . \mathrm{I}$ & 83.8 & 78.4 & $79 \cdot 3$ & $-3 \cdot 3$ \\
\hline
\end{tabular}

In 2009, in terms of government spending on health as a share of total expenditure, India, a strong economy within the Asian regions, was just ahead of Bangladesh with fourth position from the bottom (Table 1).

During the decade from 2000 to 2009, the share increased by 16 percent in India, whereas the similar figures for Malaysia, China and Philippines were at 14.5 per cent, 23.6 percent and 25.8 percent, respectively. The growth was the highest in Pakistan at 35.4 per cent. ${ }^{7}$ This share declined even in Sri Lanka, which has the best indicator of human development within the region.

This is coupled with inequitable distribution of resources. Among these twelve countries the density of nursing and midwifery personnel was highest in Philippines, followed by Malaysia and Indonesia, with Bangladesh reporting the lowest density. India occupied the sixth position (Table 2).

In India, health sector reform under National Rural Health Mission (NRHM) has introduced a few strategic innovations including strengthening of rural health facilities through an untied fund to enable local intervention at the primary level and service delivery at household level, through the Accredited Social Health Activist (ASHA). ASHAs expect to be paid incentives based on PBF to encourage Institutional delivery (ID), Antenatal Check-up and Complete Immunization. A study based on primary survey in West Bengal, India shows that the use of ASHAs and incentive scheme of Janani Surasha Yojana (JSY) have pushed up the numbers of ID significantly, but the state government has not been able to improve the availability of maternity beds, General Duty Medical Officers or Specialist gynecologists in block and sub-division level hospitals in 
Table 2: Density of Nursing and midwifery personnel/10000population in 2009-2011: ${ }^{8}$

Country

Bangladesh

Bhutan

Nepal

Pakistan

Vietnam

India

China

Thailand

Sri Lanka

Indonesia

Malaysia

Philippines
Nursing and midwifery personnel density (per Io ooo population)

Note: Data for India are from 2005, for Sri Lanka and Bangladesh 2007 and for China 2009

West Bengal, India. As a result, the risk of neonatal death appears to increase if the baby is delivered in a public hospital in the state, which renders the entire effort of health reform counterproductive. ${ }^{9}$ Additionally, utilization of non-incentivized services (like awareness for breastfeeding, contraception usage etc.) stagnates in post reform era, portraying neglect of "low hanging fruits" ${ }^{\text {"10 }}$ in developing countries.

\section{Are Inter and Intra-household Inequalities Addressed and Reduction Attempted?}

It is partially true that incentive schemes have been successful in expanding health care services across economic and social classes, thus reducing inter-household disparities. Persisting Intra-household discriminations has perpetuated limited access to health care for women. ${ }^{11}$

Bargain models clearly revealed that women who have more education, who earn more than their spouses, or who are the sole earners in their marriage have the highest likelihood of frequent and severe violence ${ }^{12}$ which seriously restrict their choice of health care services.

Similarly, studies also locate the negative impact of a mother's employment status on her child's immunization status ${ }^{13}$ contradicting the assumption that mother's employment and, hence, income, increases her awareness and raises the family's expenditure on human development.

As most of the working women in developing countries work in informal sector, they seldom enjoy any medical leave at their workplaces and hence 
invest little time and effort to their own health care. Thus the traditional development measures like education and participation in labor force assume highly non-linear relationship with health status and nature of health sector reform have not been able to break these barriers appreciably. The impact varies across regions depending upon initial status and degree of social transformation. A 'one size fits all' approach does not take into account contextual factors, such as levels of social development ("backwardness") and economic conditions, which influence the outcome of reforms. ${ }^{14}$

Realization of the limited impact of health care reforms like PBF, has brought back the issue of 'what is delivered and how it is delivered', rather than 'who delivers'.

\section{Conclusions}

Health sector reforms in India, now more than ever before, need focused attention to mend the neglect of public health and primary health care. As India joins an increasing league of countries in implementing universal health coverage for its 1.2 billion citizens over the coming decade, a key focus area of the Indian government is to reorient India's existing health system. For this it is important focus on:

- Considering again approaches and strategies of Performance based financing -on the basis of lessons learnt

- Equitable distribution of resources

- Contextual factors, such as social development ('social backwardness') and economic conditions, which influence the outcome of reforms

- Targeted actions for addressing gender inequalities

- 'What is delivered and how it is delivered', rather than 'who delivers'

The 14th World Congress on Public Health provided useful insights from public health professionals, health workers, professional bodies, non-governmental organizations, international agencies, donors, and foundations to propel action in India towards a new framework of health sector reforms.

Arijita Dutta ${ }^{a}$ and Madhumita Dobe ${ }^{b}$

aUniversity of Calcutta, Kolkata, India

${ }^{\mathrm{b}}$ Department of Health Promotion \& Education, AllH\&PH, Kolkata, India E-mail: dutta.arijita@gmail.com 


\section{Notes and References}

1. World Bank. (1993) World Development Report: Investing in Health. Washington DC: World Bank.

2. Standing, H. (1999) Frameworks for Understanding Gender Inequalities and Health Sector Reform: An Analysis and Review of Policy Issues. Cambridge, MA: Harvard Center for Population and Development Studies.

3. Hsiao, W. (2000) Inside the Black Box of Health Care Systems. Program on Health Care Financing. Boston, MA: Harvard School of Public Health.

4. Witter, S., Khadka, S., Nathand, H., \& Tiwari, S. (2011). The national free delivery policy in Nepal: early evidence of its effects on health facilities. Health Policy \& Planning. doi:10.1093/ heapol/czr066.

5. Gwatkin, D. (2009) Ensuring that the Poor Share Fully in the Benefits of Results-Based Financing Program in Health. Washingtion, D.C.: Results-Based Financing for Health.

6. WHO (2008). Scaling Up Health Services: Challenges and Choices. Draft 3. Geneva: WHO.

7. WHO (2011) World Health Report. Geneva: WHO.

8. WHO. http://apps.who.int/ghodata/, accessed 12 July 2015

9. Khasnobis, R., Dutta, A., Banerjee, S. (2014) Estimation \& Determinants of Infant Mortality Rate. Report submitted to Department of Health \& Family Welfare, Government of West Bengal.

10. Banerjee, A. (2011) Poor Economics: A Radical Thinking of the way to fight Global Poverty. New York: Public Affairs.

11. Bose, M., Dutta, A. (forthcoming) Access to Non-hospitalization Care in West Bengal. Indian Journal of Human Development in press.

12. Weitzman, A. (2014). Women's and Men's Relative Status and Intimate Partner Violence in India. Population and Development Review 40(1): 55-75.

13. Barman, D., \& Dutta, A. (2013). Access and barriers to immunization in West Bengal, India: quality matters. Journal of Health, Population and Nutrition 31(4): 510-522.

14. Standing, H. (2002). An overview of changing agendas in health sector reforms. Reproductive Health Matters 10(20): 19-28. 